\title{
Minireview
}

\section{Bioadsorption Strategies with Yeast Molecular Display Technology}

\author{
SEIJI SHIBASAKI ${ }^{1,2 *}$, AND MITSUYOSHI UEDA ${ }^{3}$ \\ ${ }^{1}$ General Education Center, Hyogo University of Health Sciences, \\ 1-3-6 Minatojima, Chuo-ku, Kobe 650-8530, Japan \\ ${ }^{2}$ Graduate School of Pharmacy, Hyogo University of Health Sciences, \\ 1-3-6 Minatojima, Chuo-ku, Kobe 650-8530, Japan \\ ${ }^{3}$ Division of Applied Life Sciences, Graduate School of Agriculture, Kyoto University, \\ Kitashirakawa-oiwakecho, Sakyo-ku, Kyoto 606-8502, Japan \\ Received 27 February, 2014/Accepted 8 April, 2014
}

\begin{abstract}
Molecular display techniques using microbial cell surfaces have been widely developed in the past twenty years, and are useful tools as whole cell catalysts for various applications such as bioconversion, bioremediation, biosensing, and the screening system of protein libraries. Furthermore, different types of microbial cells among eukaryotic and prokaryotic strains have been investigated for their use in surface display technologies. Recently, several kinds of protein-displaying yeasts have been utilized as bioadsorbents in this platform technology. In particular, these trials have successfully expanded the possibility of applications to metal binding, affinity purification, and receptor-ligand interaction by using the yeast cell surface. In this mini review, we describe the general principles of molecular display technology using yeast cells and its applications, with a particular focus on bioadsorption.
\end{abstract}

Key words : Bioadsorption / Cell surface / Saccharomyces cerevisiae / Molecular display.

\section{INTRODUCTION}

In recent decades, materials science, including macromolecular or nanochemistry, has provided functional particles as catalysts for several biological applications including ion exchange, purification, and the immobilization of bioactive compounds, among others. Considering current trends in developing sustainable technologies, reusable and convenient methods to prepare functional materials are increasingly desired. Molecular display technology using microorganism cells is considered to be a promising and sustainable approach for bioadsorption, especially for binding specific molecules with biological activity.

Molecular display technology was first developed in the 1980s, and was initially reported as phage display technology (Smith, 1985). Since then, Escherichia coli (Hofnung, 1991; Stathopoulos et al., 1996), Lactobacillus casei (Maassen et al., 1999), and other

*Corresponding author. Tel: +81-78-304-3159, Fax: +81-78304-2859, E-mail : seiji (a)huhs.ac.jp kinds of bacterial cells have been thoroughly investigated as potential surfaces for immobilizing molecules of interest. However, in some cases, handling of these bacterial cells is difficult in flow cytometry analysis because of their small cell size compared with eukaryotic cells (Shibasaki et al., 2001a). With respect to bioadsorption applications, a larger cell surface is advantageous to enable the binding of a large number of target molecules on the cell. Moreover, the quality control system of eukaryotic proteins is superior to that of prokaryotes. Therefore, eukaryotic microorganisms are more appropriate as bioadsorption materials than bacterial cells.

Here, we focus on molecular display technology using the yeast Saccharomyces cerevisiae. The yeast molecular display technology is based on genetic engineering for producing molecules of interest as a fusion protein of the cell wall proteins. To date, a wide variety of foreign proteins and peptides have been designed for such purposes; for example, bioconversion enzymes (Shibasaki, 2009; Shibasaki et al., 2009a; Shibasaki and Ueda, 2010), fluorescent reporter proteins 
(Shibasaki et al., 2001b; Shibasaki et al., 2006), vaccines (Shibasaki et al., 2013) and a combinatorial peptide library for use in screening for bioactive molecules (Matsui et al., 2009). In this mini review, we describe a bioadsorption system of yeast cells created with molecular display technology. First, we describe the underlying principle of the molecular display technology of yeasts. Then, we focus on investigations using molecular display for binding metal ions, antibodies, and receptor-ligand interactions.

\section{PRINCIPLES OF YEAST MOLECULAR DISPLAY}

The manipulation of yeast cells to display foreign proteins or peptides by genetic engineering has been called "arming yeast" (Andreu and Delolmo, 2013; Kuroda and Ueda, 2011). Host cells and anchoring proteins are important factors in this technology. In this section, we review the use of yeast molecular display technology in three different kinds of yeast cells. Then, we describe the system of $S$. cerevisiae using $a$-agglutinin as an anchor and discuss its applications for bioadsorption.

\section{Molecular display technology using S. cerevisiae}

The budding yeast, S. cerevisiae, has been long used in fermentation technology. It is not only considered a "generally regarded as safe (GRAS)" material by the US Food and Drug Administration, but is also a common assay model owing to its fungicidal activity (Shirai et al., 2012; Ueda et al. 2009). a-Agglutinin and a-agglutinin are representatives of cell wall-anchoring domains that are used for the cell surface display of target proteins/ peptides. They are involved in sexual adhesion of mating types $a$ and a cells, and have some characteristics specific to cell wall proteins (Shibasaki et al., 2009b). Specifically, they possess an N-terminal secretion signal sequence for transportation to the cell surface and C-terminal glycosylphosphatidylinositol (GPI) anchor attachment signal sequences for transient anchoring to the cell membrane (Lipke et al., 1992). These GPI-anchored proteins in the cell membrane are released via cleavage by phosphatidylinositol-specific phospholipase C (PI-PLC), and then bind to the cell wall with a covalent bond at their cell wall-anchoring domains (Fig. 1).

Many kinds of proteins/peptides, including those with relatively large molecular masses and glycosylation requirements, have been successfully displayed on the yeast cell surface using the cell wall-anchoring domain of $\alpha$-agglutinin (Aoki et al., 2011; Ueda and Tanaka, 2000). In the $a$-agglutinin-based display system, target proteins are fused to the secretion signal sequence at the

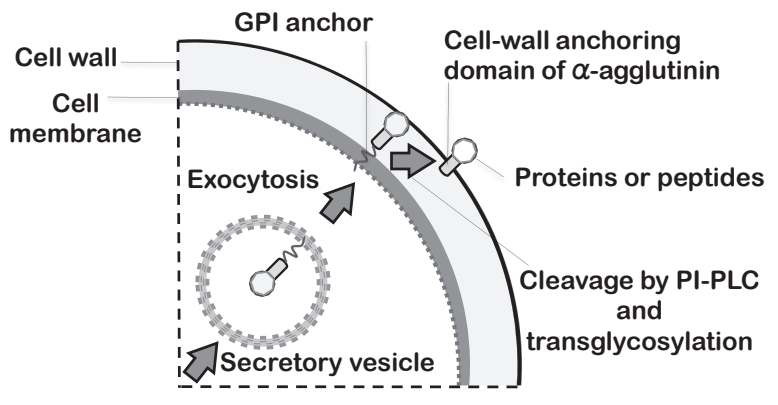

FIG. 1. General principles of $a$-agglutinin-based molecular display on the yeast cell surface.

PI-PLC; phosphoinositide phospholipase C.

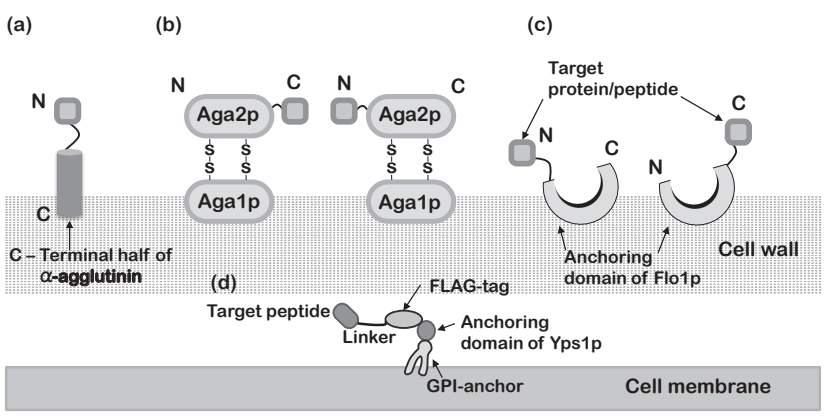

FIG. 2. Molecular display systems using S. cerevisiae. (a) aAgglutinin-based display system. (b) a-Agglutinin-based display systems. (c) Flo1p-based display systems. (d) Membrane display system by anchoring the domain of Yps1p.

$\mathrm{N}$-terminus and to the cell wall-anchoring domain at the C-terminus (Fig. 2a). Aga1p and Aga2p are linked by disulfide bonds, and provide $\mathrm{N}$ - or $\mathrm{C}$-terminal-free molecular display (Fig. 2b) (Boder and Wittrup, 1997). In addition, Flo1p, which is a GPI-anchored cell wall protein involved in flocculation, also provides $\mathrm{N}$-terminal-free display in a similar manner (Fig. 2c) (Sato et al., 2002). A truncated form of Flo1p lacking the GPI anchor attachment signal sequence can also be used for C-terminal-free display as an adhesive region (Fig. 2c) (Bleve et al., 2014).

\section{Molecular display technology using Yarrowia lipolytica}

The hemiascomycetous yeast, Y. lipolytica, has heterothallic and dimorphic characteristics and high potential for secreting heterologous proteins. Therefore, it is suitable for industrial applications. Several kinds of cell wall proteins in Y. lipolytica have been investigated for use in molecular display technology. YICWP1 and YIPIR1 from Y. lipolytica, which are GPI-anchored cell wall proteins, allow $\mathrm{N}$ - and $\mathrm{C}$-terminus-free display, respectively (Bulani et al., 2012; Yuzbasheva et al. 2011). 


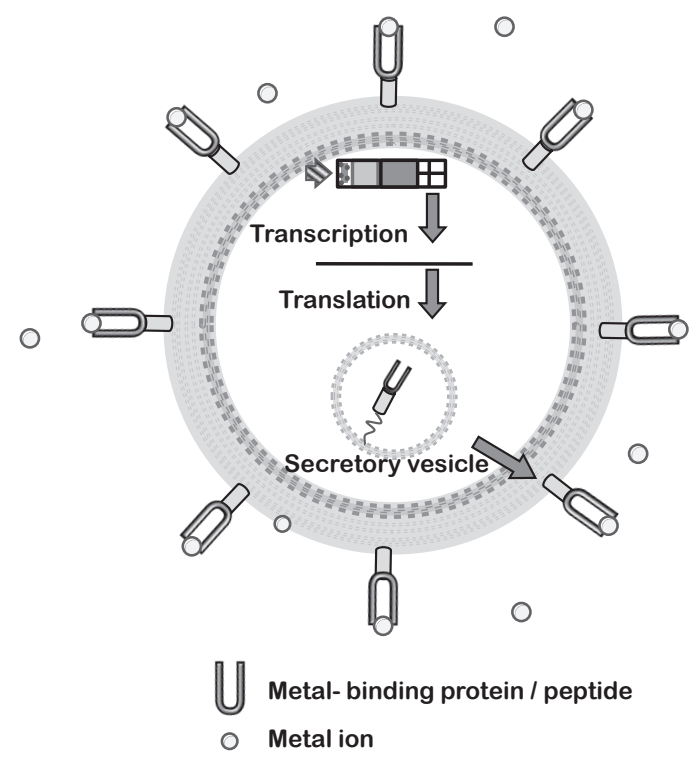

FIG. 3. Model of the yeast cell as a bioadsorbent for metal binding or bioremediation using molecular display technology.

\section{Molecular display technology using Pichia pastoris}

The methylotrophic yeast, $P$. pastoris, can proliferate on media including a simple carbon source and allows a high-density culture. Therefore, it is also a suitable host for use in large-scale fermentation cultures for molecular display technology. Both N- and C-terminusfree display systems of $P$. pastoris have been established using cell wall proteins ( $a$-agglutinin, a-agglutinin, Flo1p, Sed1p, and Tip1p) from S. cerevisiae, as described above (Su et al., 2010; Tanino et al., 2006).

\section{BIOADSORPTION OF METAL IONS}

\section{Cell surface design for the bioadsorption of metal ions}

The cell-surface adsorption of metal ions (Fig. 3) has been investigated as an alternative strategy to bioaccumulation. To achieve the bioremediation of metalpolluted water, various metal-binding proteins or peptides have been displayed on the microbial cell surfaces of E. coli, Ralstonia eutropha, S. cerevisiae, Staphylococcus xylosus, and Staphylococcus carnosus, such as metallothioneins (Kuroda and Ueda, 2006; Valls et al., 2000), mercury-responsive metalloregulatory proteins (Bae et al., 2003), hexa-histidine (Kuroda et al., 2001; Samuelson et al., 2000), histidine-rich peptides (GHHPHG; HP), and cysteine-rich peptides (GCGCPCGCG; CP) (Kotrba et al., 1999). The genetic strategy for metal ion bioadsorption in the case of a yeast cell is shown in Fig. 4. Moreover, the molecular display of yeast was also used for cellular aggregation in response to environmental metal ions (Kuroda et al.,

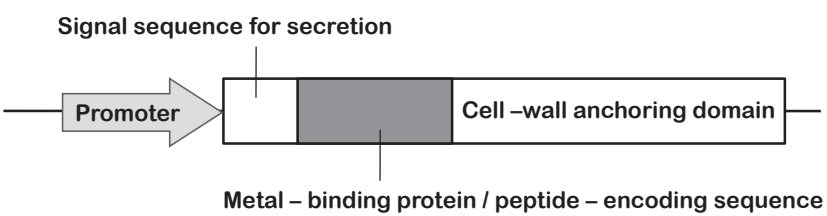

FIG. 4. Genetic construction for cell-surface display of metalbinding proteins and peptides on the yeast cell surface.

2002).

\section{Bioadsorption for the recovery of rare metal ions}

Several rare metal ions are essential for maintaining the physiological function of living cells. For example, molybdate plays an important role in the active center of the molybdopterin cofactor of several enzymes (Kozmin et al., 2000). In E. coli, molybdenum uptake is controlled by the transcription factor ModE, which binds to molybdate and regulates the expression of the Mod operon (Tao et al., 2005). The molecular display of fulllength ModE or its C-terminal domain was investigated to achieve molybdate adsorption on the cell surface (Nishitani et al., 2010). The adsorbed molybdate on the cell surface was successfully recovered by treating the cell with papain after adsorption. Moreover, these papain-treated cells could be recultivated and reused.

\section{Modification of metal-binding molecules on the cell surface}

In addition to the direct use of existing proteins on the yeast cell surface, novel proteins or known proteins that are improved with specific or modified binding abilities (Kuroda et al. 2012) can be synthesized to enhance specific adsorption properties. The advantage of using proteins for metal binding is the flexibility of the binding domain. In the creation of novel proteins, the molecular display system is also a very useful tool that facilitates preparation and direct analysis of proteins on cells without requiring purification or concentration processes (Ueda, 2004; Wittrup, 2001). Therefore, proteindisplaying cells can be treated as microparticles that are covered with proteins. These cells could be particularly useful for high-throughput screening of protein libraries for the selection of clones with desired functions (Matsui et al., 2009). Novel binding peptides have been created for gold, nickel, cadmium, and zinc ions from a random peptide library using a molecular display system (Brown, 1997; Kjaergaard et al., 2001; Mejare et al., 1998). Considering the specific binding of target metal ions, specific proteins such as metal sensor proteins and transcription factors that regulate the expression of downstream genes in response to cellular metal ions could be utilized as a more useful resource than peptides. This is because these metal-responsive 

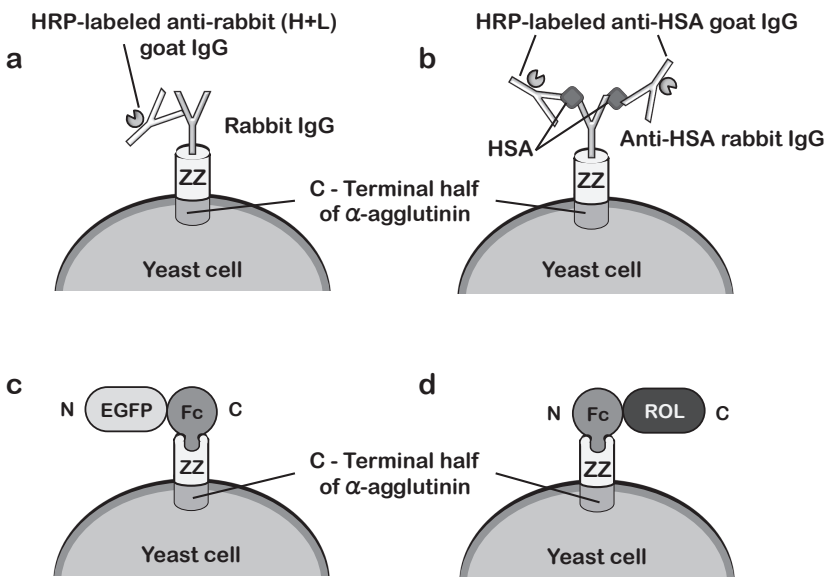

FIG. 5. Schematic illustrations of (a) ELISA to detect rabbit IgG and (b) sandwich ELISA to detect HSA using yeast cells displaying the ZZ domain. HRP; horseradish peroxidase, IgG; immunoglobulin G, HSA; human serum albumin. Affinity binding between the $Z Z$ domain on the yeast cell surface and (c) the EGFP-Fc fusion protein or (d) the Fc-ROL (lipase) fusion protein.

transcription factors show not only specific binding but also the dissociation of metal ions. Dissociation is an important factor in the recovery of enriched target metal ions after bioadsorption from aqueous solutions.

\section{ANTIBODY BIOADSORPTION}

Antibody molecules, especially immunoglobulin $G$ ( $\lg G)$, are widely used for biochemical studies, for example, in diagnosis or as therapeutics (Shibasaki and Ueda, 2009; Ueda et al., 2013). Previously, using molecular display technology, we created yeast cells displaying the ZZ domain derived from Staphylococcus aureus Protein $A$, which binds to the Fc part of $\mathrm{lgG}$ (Nilsson et al., 1987). The ZZ domain has a repetitive structure of the small $Z$ domain (58 amino acid residues), which consists of three $a$-helical domains. The $\mathrm{ZZ}$ protein can interact with IgG from various species including humans (IgG1, IgG2, and IgG4) and rabbits (all lgG classes) (Kronvall and Williams, 1969). The ZZ protein has been used as an affinity module to purify recombinant proteins and as immunoassays. Therefore, S. cerevisiae cells displaying the ZZ domain could be widely used in immunoassays and affinity purification as an immunoadsorbent.

\section{Immunoadsorbent for enzyme-linked immunosor- bent assays (ELISAs)}

To examine the applicability of yeast cells displaying the ZZ domain as an immunoadsorbent (Kikuchi et al., 2013), an ELISA was conducted for detection of rabbit IgG (Fig. 5a) with a concentration range of approxi- a

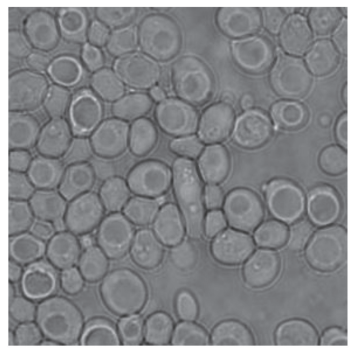

b

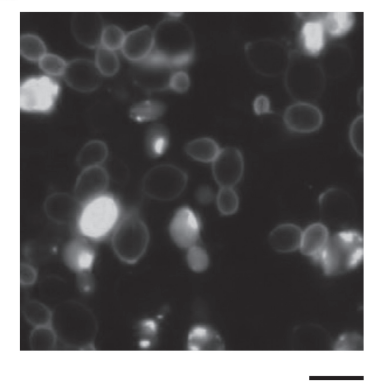

FIG. 6. Microscopic observation after cocultivation of the $Z Z$ domain-displaying cell and EGFP-Fc fusion protein-secreting cell. (a) Light field micrograph, (b) fluorescence micrograph. Bar ; $5 \mu \mathrm{m}$

mately $1-10^{5} \mathrm{ng} / \mathrm{ml}$ (Nakamura et al., 2001). After a 5-min incubation, the amount of bound IgG reached a plateau, indicating that the binding of $\lg G$ to yeast cells displaying the $\mathrm{ZZ}$ domain is very rapid, demonstrating the advantage of this system in terms of reducing assay time. By changing the amount of cells used in the assay and the reaction time with a horseradish peroxidase substrate, the detection range of rabbit lgG concentration varied between 10 and $10^{4} \mathrm{ng} / \mathrm{ml}$. Only a small amount of cells is required to detect rabbit lgG concentration as low as $1-10 \mathrm{ng} / \mathrm{ml}$.

Since the ZZ molecule is capable of binding antibodies from a wide range of species, yeast cells displaying the ZZ domain are applicable to the detection of a variety of antigens by using the sandwich detection method, as shown in Fig. 5b. In this example, sandwich ELISA was used to detect human serum albumin (HSA). Similar to the ELISA detection of IgG, a detection limit of $1-10 \mathrm{ng} / \mathrm{ml}$ HSA could be achieved by increasing the amount of cells and the reaction time (Nakamura et al., 2001).

\section{Affinity purification}

We explored the most suitable strain and optimal cultivation conditions for applying ZZ domain-displaying cells to affinity purification (Shibasaki et al., 2007). In addition, as an alternative model of affinity purification to IgG, we demonstrated that the ZZ domain-displaying yeast cells could be used to bind and recover the FC fragment-fused protein that is produced extracellularly by other recombinant cells (Fig. 5c). The Fc fragment was fused to the C-terminus of enhanced green fluorescent protein (EGFP) and secreted into the medium. The ZZ domain-displaying cell was simultaneously cultivated in the same flask, and the EGFP-FC fusion protein secreted by another strain was fixed on the cell surface of the ZZ domain-displaying cell (Fig. 6). After the cells were treated with an acidic solution, fluorescence was 
observed in the eluted and neutralized fraction. These results demonstrated that the Fc fusion protein could be precisely bound to the $\mathrm{ZZ}$ domain displayed on the cell surface, and it could be separated and recovered by simple cultivation. The Fc-lipase fusion protein, for example, was also bound to the cell surface, and the recovery of lipase was confirmed (Fig. 5d). This synergistic production and recovery system of the Fc fusion protein using yeast cells that display a high amount of the ZZ domain provides a convenient and cost-efficient system for obtaining secreted recombinant proteins for biotechnological or pharmaceutical applications. Another module based on affinity binding between cohesin and dockerin is a suitable alternative to the Fc-ZZ combination (Ito et al., 2009).

\section{BIOADSORPTION USING THE RECEPTOR-LIGAND AFFINITY INTERACTION}

The binding between a receptor and a ligand can be regarded as a representative bioadsorption process occurring in physiological processes. Genetic engineering for immobilization of a receptor requires two aspects: recovering ligand molecules, and transplantation of its function for controlling the signal transduction of host cells.

\section{Bioadsorption between a hormone and its receptor}

Endocrine disruptors perturb natural endocrine function. They have become a major public health concern because of their potential to disrupt physiological processes, particularly through direct interactions with steroid hormone receptors (Amaro et al., 2014). Recently, the biodegradation potential of such compounds has been investigated (Matsumura et al., 2009; Watanabe et al., 2012). To evaluate the ability of chemical compounds to act as endocrine disruptors and bind steroid hormone receptors, various in vivo and in vitro assay tools have been developed and used to determine their estrogenicity (Routledge and Sumpter 1997; Sohoni and Sumpter 1998; Nishikawa et al. 1999). A yeast strain containing the ligand-binding domain of the rat estrogen receptor (ERLBD) was developed to establish a new assay system of endocrine disruptors (Yasui et al., 2002). A binding assay was performed using fluorescent $17 \beta$-estradiol (17-FE) in order to examine whether cells displaying ERLBD on the cell surface could entrap hormone-like compounds. $17-\mathrm{FE}$ is an analogue of the natural ligand of the estrogen receptor. The fluorescence intensity of cells displaying ERLBD was near saturation at over $150 \mathrm{nM}$ 17-FE using $9.7 \times 10^{7}$ cells, as shown in Fig. 7 . The calculation indicated that cells displaying ERLBD on the

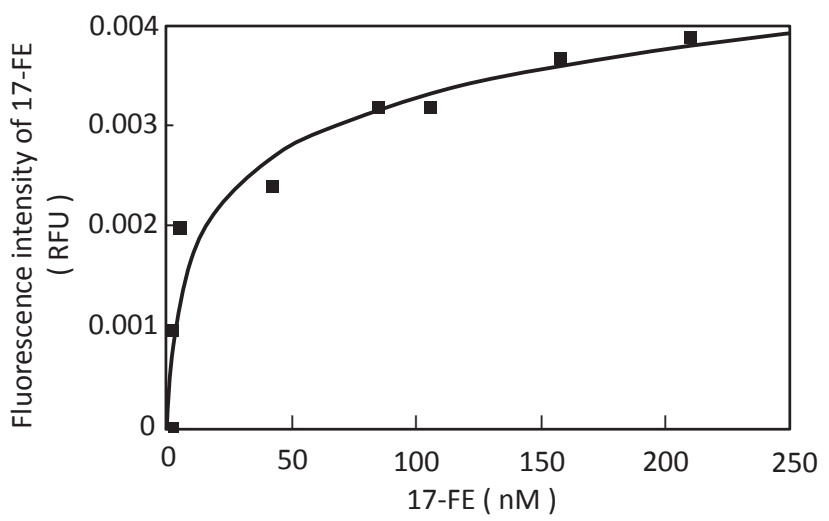

FIG. 7. Fluorescence intensity of fluorescent $17 \beta$-estradiol (17-FE) bound on the receptor-displaying cells. The binding ability of 17 -FE to the cells $\left(9.7 \times 10^{7}\right.$ cells $)$ was evaluated at various 17-FE concentrations. RFU; relative fluorescence unit.

cell surface were saturated at $9.5 \times 10^{4}$ molecules/cell. This is very similar to the number of green fluorescent proteins on the cell surface of another surface-engineered yeast (Shibasaki et al., 2001b). The number of 17-FE molecules entrapped on the cell surface suggested that a system based on this ERLBDdisplaying yeast would be useful not only for screening hormone-like compounds through competitive experiments, but also for removing these polluting compounds from the environment.

\section{Application for display of a receptor and a ligand on the cell surface}

$G$ protein-coupled receptors (GPCRs) have the ability to mediate rapid responses to extracellular signals, and they play an important role in many cellular functions. In the study of ligand-GPCR interactions and identification of ligands against orphan GPCRs, specific display of peptide ligands on the plasma membrane is desired. A peptide-ligand display system for the activation of GPCR signaling on the yeast plasma membrane has been developed (Hara et al., 2012a; Morioka et al., 2013).

First, this system was applied to the activation of Ste2 signaling in S. cerevisiae, where the activation was detected by using a Ste2-responsive FUS1 promoter driving EGFP-reporter expression. The $a$-factor displayed on the plasma membrane was demonstrated to activate the pheromone response pathway. In addition, this system has been applied to the activation of human GPCR signaling as well as the yeast pheromone response pathway using chimeric Ga protein. Somatostatin is a gastrointestinal hormone that regulates a wide variety of endocrine and exocrine processes. Somatostatin was displayed on the plasma membrane of yeast cells producing human somatostatin 


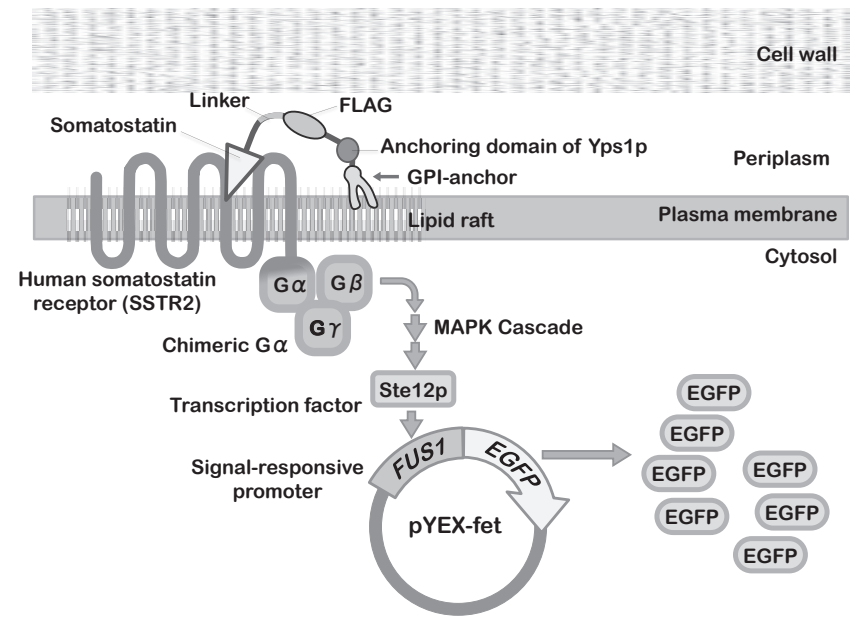

FIG. 8. Signal activation of human somatostatin receptor subtype-2 by membrane-displayed somatostatin. Membranedisplayed somatostatin activates human somatostatin receptor subtype-2, which is heterologously produced in yeast, and leads to the activation of chimeric Ga proteins, the mitogen-activated protein kinase cascade, and transcription factor Ste12p. Phosphorylated Ste12p induces the overexpression of EGFP by binding to a pheromone response element in the FUS1 promoter.

receptor subtype-2 (SSTR2) and chimeric Ga protein. Moreover, the somatostatin displayed on the plasma membrane could effectively activate human SSTR2 in S. cerevisiae (Hara et al., 2012b) (Fig. 8). This platform shows promise for the identification of novel peptide ligands for heterologously produced GPCRs, and for screening libraries based on the activation of reporter genes.

\section{CONCLUSION}

The principles of molecular display technology using yeast cells and its application in bioadsorption were reviewed. This technology can provide a wide variety of proteins or peptides for the convenient adsorption of a target molecule on the yeast cell surface if the genetic information of the protein or peptide sequence of interest is available. Although this article focused on fundamental applications of adsorption techniques using yeast molecular display systems, environmental solutions could be also achieved with similar systems such as using a phosphorus adsorbent as an antimicrobial agent (Ohmoto et al., 2012). Indeed, we have also investigated a phosphate-dependent molecular display method using the $\mathrm{PHO}$ gene (Shibasaki et al., 2001a) and displayed organophosphorus hydrolase (Fukuda et al., 2010). The results suggested that the display of any phosphate-binding proteins could be developed for use with novel phosphorus adsorbents as the antimicrobial material.

Thus, the yeast molecular display system is steadily emerging as one of the most powerful bioadsorbent tools for use in many industrial, environmental, and fundamental applications.

\section{REFERENCES}

Amaro, A. A., Esposito, A. I., Mirisola, V., Mehilli, A., Rosano, C., Noonan, D. M., Albini, A., Pfeffer, U., and Angelini, G. (2014) Endocrine disruptor agent nonyl phenol exerts an estrogen-like transcriptional activity on estrogen receptor positive breast cancer cells. Curr. Med. Chem., 21, 630-640.

Andreu, C., and Del Olmo, M. (2013) Yeast arming by the Aga2p system: effect of growth conditions in galactose on the efficiency of the display and influence of expressing leucine-containing peptides. Appl. Microbiol. Biotechnol., 97, 9055-9069.

Aoki, W., Yoshino, Y., Morisaka, H., Tsunetomo, K., Koyo, H., Kamiya, S., Kawata, N., Kuroda, K., and Ueda, M. (2011) High-throughput screening of improved protease inhibitors using a yeast cell surface display system and a yeast cell chip. J. Biosci. Bioeng., 111, 16-18.

Bae, W., Wu, C. H., Kostal, J., Mulchandani, A., and Chen, W. (2003) Enhanced mercury biosorption by bacterial cells with surface-displayed MerR. Appl. Environ. Microbiol., 69, 3176-3180.

Bleve, G., Lezzi, C., Spagnolo, S., Rampino, P., Perrotta, C., Mita, G., and Grieco, F. (2014) Construction of a laccase chimerical gene: Recombinant protein characterization and gene expression via yeast surface display. Appl. Biochem. Biotechnol., published on line; 2014 Jan 24. [DOI 10.1007/s12010-014-0734-4].

Boder, E. T., and Wittrup, K. D., (1997) Yeast surface display for screening combinatorial polypeptide libraries. Nat. Biotechnol., 15, 553-557.

Brown, S. (1997) Metal-recognition by repeating polypeptides. Nat. Biotechnol., 15, 269-272.

Bulani, S. I., Moleleki, L., Albertyn, J., and Moleleki, N. (2012) Development of a novel rDNA based plasmid for enhanced cell surface display on Yarrowia lipolytica. AMB Express, 2, 27.

Fukuda, T., Tsuchiyama, K., Makishima, H., Takayama, K., Mulchandani, A., Kuroda, K., Ueda, M., and Suye, S. (2010) Improvement in organophosphorus hydrolase activity of cell surface-engineered yeast strain using Flo1p anchor system. Biotechnol. Lett., 32, 655-659.

Hara, K., Ono, T., Kuroda, K., and Ueda, M. (2012a) Membrane-displayed peptide ligand activates the pheromone response pathway in Saccharomyces cerevisiae. J. Biochem., 151, 551-557.

Hara, K., Shigemori, T., Kuroda, K., and Ueda, M. (2012b) Membrane-displayed somatostatin activates somatostatin receptor subtype-2 heterologously produced in Saccharomyces cerevisiae. AMB Express, 2, 63.

Hofnung, M. (1991) Expression of foreign polypeptides at the Escherichia coli cell surface. Methods. Cell Biol., 34, 77-105.

Ito, J., Kosugi, A., Tanaka, T., Kuroda, K., Shibasaki, S., Ogino, C., Ueda, M., Fukuda, H., Doi, R. H., and Kondo, A. (2009) Regulation of the display ratio of enzymes on the Saccharomyces cerevisiae cell surface by the immunoglobulin $G$ and cellulosomal enzyme binding domains. Appl. 
Environ. Microbiol., 75, 4149-4154.

Kikuchi, Y., Ohnishi, T., Furusawa, H., Kawai, T., Fukuda, Y., Yokoyama, H., and Sugita-Konishi, Y. (2013) ELISA detection of Kudoa septempunctata in raw Paralichthys olivaceus (olive flounder) using a chicken anti-Kudoa antiserum. Biocontrol Sci., 18, 193-197.

Kjaergaard, K., Schembri, M. A., and Klemm, P. (2001) Novel $\mathrm{Zn}^{2+}$-chelating peptides selected from a fimbriadisplayed random peptide library. Appl. Environ. Microbiol., 67, 5467-5473.

Kotrba, P., Doleckova, L., de Lorenzo, V., and Ruml, T. (1999) Enhanced bioaccumulation of heavy metal ions by bacterial cells due to surface display of short metal binding peptides. Appl. Environ. Microbiol., 65, 1092-1098.

Kozmin, S. G., Pavlov, Y.I., Dunn, R. L., and Schaaper, R. M. (2000) Hypersensitivity of Escherichia coli Delta (uvrB-bio) mutants to 6-hydroxylaminopurine and other base analogs is due to a defect in molybdenum cofactor biosynthesis. J. Bacteriol., 182, 3361-3367.

Kronvall, G., and Williams, R. C. Jr. (1969) Differences in anti-protein A activity among IgG subgroups. J. Immunol., 103, 828-833.

Kuroda, K., Shibasaki, S., Ueda, M., and Tanaka, A. (2001) Cell surface-engineered yeast displaying a histidine oligopeptide (hexa-His) has enhanced adsorption of and tolerance to heavy metal ions. Appl. Microbiol. Biotechnol., 57, 697-701.

Kuroda, K., Ueda, M., Shibasaki, S., and Tanaka, A. (2002) Cell surface-engineered yeast with ability to bind, and selfaggregate in response to, copper ion. Appl. Microbiol. Biotechnol., 59, 259-264.

Kuroda, K., and Ueda, M. (2006) Effective display of metallothionein tandem repeats on the bioadsorption of cadmium ion. Appl. Microbiol. Biotechnol., 70, 458-463.

Kuroda, K., and Ueda, M. (2011) Cell surface engineering of yeast for applications in white biotechnology. Biotechnol. Lett., 33, 1-9.

Kuroda, K., Nishitani, T., and Ueda, M. (2012) Specific adsorption of tungstate by cell surface display of the newly designed ModE mutant. Appl. Microbiol. Biotechnol., 96 , 153-159.

Lipke, P. N., and Kurjan, J. (1992) Sexual agglutination in budding yeasts: structure, function, and regulation of adhesion glycoproteins. Microbiol. Rev., 56, 180-194.

Maassen, C. B., Laman, J. D., den Bak-Glashouwer, M. J., Tielen, F. J., van Holten-Neelen, J.C., Hoogteijling, L., Antonissen, C., Leer, R.J., Pouwels, P.H., Boersma, W.J., and Shaw, D. M. (1999) Instruments for oral disease-intervention strategies: recombinant Lactobacillus casei expressing tetanus toxin fragment $\mathrm{C}$ for vaccination or myelin proteins for oral tolerance induction in multiple sclerosis. Vaccine, 17, 2117-2128.

Matsui, K., Kuroda, K., and Ueda, M. (2009) Creation of a novel peptide endowing yeasts with acid tolerance using yeast cell-surface engineering. Appl. Microbiol. Biotechnol., 82, 105-113.

Matsumura, Y., Hosokawa, C., Sasaki-Mori, M., Akahira, A., Fukunaga, K., Ikeuchi, T., Oshiman, K., and Tsuchido, T. (2009) Isolation and characterization of novel bisphenol-Adegrading bacteria from soils. Biocontrol Sci., 14, 161-169.

Mejare, M., Ljung, S., and Bulow, L. (1998) Selection of cadmium specific hexapeptides and their expression as OmpA fusion proteins in Escherichia coli. Protein Eng., 11, 489-494.

Morioka, S., Shigemori, T., Hara, K., Morisaka, H., Kuroda, K. and Ueda, M. (2013) Effect of sterol composition on the activity of the yeast G-protein-coupled receptor Ste2. Appl. Microbiol. Biotechnol., 97, 4013-4020.

Nakamura, Y., Shibasaki, S., Ueda, M., Tanaka, A., Fukuda, H., and Kondo, A. (2001) Development of novel whole-cell immunoadsorbents by yeast surface display of the IgG-binding domain. Appl. Microbiol. Biotechnol., 57, 500-505.

Nilsson, B., Moks, T., Jansson, B., Abrahmsén, L., Elmbrad, A., Holmgren, E., Henrichson, C., Jones, T.A., and Uhlén, M. (1987) A synthetic IgG binding domain based on staphylococcal protein A. Prot. Eng., 1, 107-113.

Nishitani, T., Shimada, M., Kuroda, K., and Ueda, M. (2010) Molecular design of yeast cell surface for adsorption and recovery of molybdenum, one of rare metals. Appl. Microbiol. Biotechnol., 86, 641-648.

Nishikawa, J., Saito, K., Goto, J., Dakeyama, F., Matsuo, M., and Nishihara, T. (1999) New screening methods for chemicals with hormonal activities using interaction of nuclear hormone receptor with coactivator. Toxicol. Appl. Pharmacol., 154, 76-83.

Ohmoto, T., Yamashita, K., Moriyoshi, K., Yamanaka, H. Koma, D., Kawano, H., and Sakai, K. (2012) Antimicrobial action of a unique phosphorus-adsorbent additive for resin, and the mechanism of its antimicrobial effect. Biocontrol Sci., 17, 37-44.

Routledge, E. J., and Sumpter, J. P. (1997) Structural features of alkylphenolic chemicals associated with estrogenic activity. J. Biol. Chem., 272, 3280-3288.

Samuelson, P., Wernerus, H., Svedberg, M., and Ståhl, S. (2000) Staphylococcal surface display of metal-binding polyhistidyl peptides. Appl. Environ. Microbiol., 66, 1243-1248.

Sato, N., Matsumoto, T., Ueda, M., Tanaka, A., Fukuda, H., and Kondo, A. (2002) Long anchor using Flo1 protein enhances reactivity of cell surface-displayed glucoamylase to polymer substrates. Appl. Microbiol. Biotechnol., 60, 469-474.

Shibasaki, S., Ninomiya, Y., Ueda, M., Iwahashi, M., Katsuragi, T., Tani, Y., Harashima, S., and Tanaka, A. (2001a) Intelligent yeast strains with the ability to selfmonitor the concentrations of intra- and extracellular phosphate or ammonium ion by emission of fluorescence from the cell surface. Appl. Microbiol. Biotechnol., 57, 702-707.

Shibasaki, S., Ueda, M., lizuka, T., Hirayama, M., Ikeda, Y., Kamasawa, N., Osumi, M., and Tanaka, A. (2001b) Quantitative evaluation of the enhanced green fluorescent protein displayed on the cell surface of Saccharomyces cerevisiae by fluorometric and confocal laser scanning microscopic analyses. Appl. Microbiol. Biotechnol., 55, 471-475.

Shibasaki, S., Kuroda, K., Duc Nguyen, H., Mori, T., Zou, W., and Ueda, M. (2006) Detection of protein-protein interactions by a combination of a novel cytoplasmic membrane targeting system of recombinant proteins and fluorescence resonance energy transfer. Appl. Microbiol. Biotechnol., 70, 451-457.

Shibasaki, S., Kawabata, A., Ishii, J., Yagi, S., Kadonosono, T., Kato, M., Fukuda, N., Kondo, A., and Ueda, M. (2007) Construction of a novel synergistic system for production and recovery of secreted recombinant proteins by the cell surface engineering. Appl. Microbiol. Biotechnol., 75, 821-828.

Shibasaki, S. (2009) Development of platform technology using molecular display. Yakugaku Zasshi, 129, 1333-1340.

Shibasaki, S., Kawabata, A., Tanino, T., Kondo, A., Ueda, M., and Tanaka, M. (2009a) Evaluation of the biodegradability 
of polyurethane and its derivatives by using lipasedisplaying arming yeast. Biocontrol Sci., 14, 171-175.

Shibasaki, S., Maeda, H., and Ueda, M. (2009b) Molecular display technology using yeast-arming technology. Anal. Sci., 25, 41-49.

Shibasaki, S., and Ueda, M. (2009) Therapeutic antibodies and other proteins obtained by molecular display technology. Recent Pat. Biotechnol., 3, 19-27.

Shibasaki, S., and Ueda, M. (2010) Development of yeast molecular display systems focused on therapeutic proteins, enzymes, and foods: functional analysis of proteins and its application to bioconversion. Recent Pat. Biotechnol., 4, 198-213.

Shibasaki, S., Aoki, W., Nomura, T., Miyoshi, A., Tafuku, S., Sewaki, T., and Ueda, M. (2013) An oral vaccine against candidiasis generated by a yeast molecular display system. Pathog. Dis., 69, 262-268.

Shirai, A., Ueta, S., Maseda, H., Kourai, H., and Omasa, T. (2012) Action of reactive oxygen species in the antifungal mechanism of gemini-pyridinium salts against yeast. Biocontrol Sci., 17, 77-82.

Smith, G. P. (1985) Filamentous fusion phage: Novel expression vectors that display cloned antigens on the virion surface. Science, 228, 1315-1317.

Sohoni, P., and Sumpter, J. P. (1998) Several environmental oestrogens are also anti-androgens. J. Endocrinol., 158, 327-339.

Stathopoulos, C., Georgiou, G., and Earhart, C. F. (1996) Characterization of Escherichia coli expressing an Lpp'OmpA (46-159)-PhoA fusion protein localized in the outer membrane. Appl. Microbiol. Biotechnol., 45, 112-119.

Su, G. D., Zhang, X., and Lin, Y. (2010) Surface display of active lipase in Pichia pastoris using Sed1 as an anchor protein. Biotechnol. Lett., 32, 1131-1136.

Tanino, T., Fukuda, H., and Kondo, A. (2006) Construction of a Pichia pastoris cell-surface display system using Flo1p anchor system. Biotechno. Prog., 22, 989-993.

Tao, H., Hasona, A., Do, P.M., Ingram, L.O., and
Shanmugam, K. T. (2005) Global gene expression analysis revealed an unsuspected deo operon under the control of molybdate sensor, ModE protein, in Escherichia coli. Arch. Microbiol., 184, 225-233.

Ueda, M. (2004) Future direction of molecular display by yeast-cell surface engineering. J. Mol. Catal. B, 28, 139-143.

Ueda, M., and Tanaka, A. (2000) Cell surface engineering of yeast: Construction of arming yeast with biocatalyst. J. Biosci. Bioeng., 90, 125-136.

Ueda, S., Iwase, M., and Kuwabara, Y. (2013) Evaluation of immunochromatography for the rapid and specific identification of Listeria monocytogenes from food. Biocontrol Sci., 18, 157-161.

Ueda, T., Hara, M., Odagawa, I., and Shigihara, T. (2009) Simultaneous treatment of washing, disinfection and sterilization using ultrasonic levitation, silver electrolysis and ozone oxidation. Biocontrol Sci., 14, 1-12.

Valls, M., Atrian, S., de Lorenzo, V., and Fernandez, L.A. (2000) Engineering a mouse metallothionein on the cell surface of Ralstonia eutropha $\mathrm{CH} 34$ for immobilization of heavy metals in soil. Nat. Biotechnol., 18, 661-665.

Watanabe, W., Hori, Y., Nishimura, S., Takagi, A., Kikuchi, M., and Sawai, J. (2012) Bacterial degradation and reduction in the estrogen activity of 4-nonylphenol. Biocontrol Sci., 17, 143-147.

Wittrup, K. D. (2001) Protein engineering by cell-surface display. Curr. Opin. Biotechnol., 12, 395-399.

Yasui, M., Shibasaki, S., Kuroda, K., Ueda, M., Kawada, N., Nishikawa, J., Nishihara, T., and Tanaka, A. (2002) An arming yeast with the ability to entrap fluorescent 17 betaestradiol on the cell surface. Appl. Microbiol. Biotechnol., 59, 329-331.

Yuzbasheva, E. Y., Yuzbashev, T. V., Laptev, I. A., Konstantinova, T. K., and Sineoky, S. P. (2011) Efficient cell surface display of Lip2 lipase using C-domains of glycosylphosphatidylinositol-anchored cell wall proteins of Yarrowia lipolytica. Appl. Microbiol. Biotechnol., 91, 645-654. 